\title{
Synthesis and Characterization of Flower-Like Bundles of ZnO Nanosheets by a Surfactant-Free Hydrothermal Process
}

\author{
Jijun Qiu, ${ }^{1,2}$ Binbin Weng, ${ }^{1}$ Lihua Zhao, ${ }^{1}$ Caleb Chang, ${ }^{1}$ Zhisheng Shi, ${ }^{1}$ Xiaomin Li, \\ Hyung-Kook Kim, ${ }^{2,4}$ and Yoon-Hwae Hwang ${ }^{2,4}$ \\ ${ }^{1}$ School of Electrical \& Computer Engineering, University of Oklahoma, Norman, OK 73019, USA \\ ${ }^{2}$ RCDAMP, Pusan National University, Busan 609-735, Republic of Korea \\ ${ }^{3}$ The State Key Laboratory of High Performance Ceramics and Superfine Microstructure, Shanghai Institute of Ceramics, \\ Chinese Academy of Sciences, Shanghai 200050, China \\ ${ }^{4}$ Department of Nano-Materials Engineering \& BK 21 Nano Fusion Technology Division, Pusan National University, \\ Miryang 627-706, Republic of Korea
}

Correspondence should be addressed to Hyung-Kook Kim; hkkim@pusan.ac.kr and Yoon-Hwae Hwang; yhwang@pusan.ac.kr

Received 14 January 2014; Accepted 12 June 2014; Published 22 December 2014

Academic Editor: Michael Z. Hu

Copyright (c) 2014 Jijun Qiu et al. This is an open access article distributed under the Creative Commons Attribution License, which permits unrestricted use, distribution, and reproduction in any medium, provided the original work is properly cited.

\begin{abstract}
Flower-like bundles of $\mathrm{ZnO}$ nanosheets have been prepared by using preheating hydrothermal process without any surfactants. The flower-like bundles consist of many thin and uniform hexagonal-structured $\mathrm{ZnO}$ nanosheets, with a thickness of $50 \mathrm{~nm}$. The selected area electronic diffraction (SAED) and high-resolution transmission electron microscope (HRTEM) images indicate that the $\mathrm{ZnO}$ nanosheets are single crystal in nature. The growth mechanism of the flower-like bundles of $\mathrm{ZnO}$ nanosheets is discussed based on the morphology evolution with growth times and reaction conditions. It is believed that the formation of flower-like bundles of $\mathrm{ZnO}$ nanosheets is related to the shielding effect of $\mathrm{OH}^{-}$ions and the self-assembly process, which is dominated by a preheating time. Room temperature photoluminescence spectra results show that the annealing atmosphere strongly affects the visible emission band, which is sensitive to intrinsic and surface defects, especially oxygen interstitials, in flower-like bundles of $\mathrm{ZnO}$ nanosheets.
\end{abstract}

\section{Introduction}

One of the most important goals of nanoscience and nanotechnology is to develop simpler method for a largescale synthesis of nanomaterials with full control of size and morphology, because size, shape, and crystal structure are crucial factors in determining the chemical, opti$\mathrm{cal}$, and electrical properties of nanoscale materials [1-4]. Recently, $\mathrm{ZnO}$ nanostructure, with a wide direct band gap and strong excitonic binding energy, has attracted much attention because of its promising characteristics for applications in electronic, photonic, and spintronic nanodevices. So far, various $\mathrm{ZnO}$ nanostructures, including nanowires [5], nanorods [6], nanonails [7], nanobridges [7], nanoprisms [8], nanotubes [9], nanobelts [3], nanorings [10], nanowhiskers [11], nanocombs [12, 13], nanohelixes [14], nanosprings [14], nanopropeller [15], nanobows [16], nanocages [17], nanodisk [18], nanopoins [19], and nanopores [20], have been fabricated by using vapor-phase process and solution phase route. Vapor-phase process such as molecular beam epitaxy (MBE) [21], metal-organic chemical vapor deposition (MOCVD) [22], sputtering method [23], pulsed laser deposition (PLD) [24], infrared irradiation [25], thermal decomposition [26], and thermal evaporation and condensation [27] is favored for their simplicity and high quality products. However these methods generally require high temperatures, high vacuums, rigorous procedures, and expensive pieces of equipment, which may limit potential applications, particularly requiring large-scale production. In contrast to the hightemperature vapor-phase process, the solution phase routes, which are based on a wet chemical and a bottom-up process, have been proved to be effective and convenient in 
preparing various $\mathrm{ZnO}$ nanostructures due to their low growth temperature, low cost, and potential for scale-up. So far hydrothermal decomposition [28, 29], electrochemical reaction [30], and template-assisted sol-gel process have been employed to synthesize $\mathrm{ZnO}$ nanowires and nanorods. Additionally, more complex and aesthetic $\mathrm{ZnO}$ nanostructures, for example, flower-like nanostructures [31-34], hierarchically branched 2D nanostructures [35-38], 3D hollow micro- and nanospheres [39-43], also have been successfully synthesized by introducing organic surfactants during solution phase synthesis. From a thermodynamic point of view, surfactants, such as trisodium citrate, ethylenediamine, poly (ethylene glycol), and cetyltrimethylammonium bromide, can change the surface free energy of different $\mathrm{ZnO}$ crystal faces and control the rates of nucleation and growth, leading to their preferential growth or elimination. Although flower-like bundles of $\mathrm{ZnO}$ nanorods or needles or sheets have been intensively reported by using surfactant-free hydrothermal method [44-47] and ZnO flowers made up of thin nanosheets were fabricated by using organic solvent at high temperature $\left(180^{\circ} \mathrm{C}\right)$ [48], it is also a challenge to fabricate flowerlike bundles of $\mathrm{ZnO}$ nanosheets by surfactant-free aqueous solution phase method at low growth temperature.

The main goal of our research is to synthesize complex $\mathrm{ZnO}$ nanostructures using a surfactant-free hydrothermal method and to study their optical properties and applications. In this paper, we report the fabrication of flower-like $\mathrm{ZnO}$ architectures, which are made of thin nanosheets, by using a surfactant-free hydrothermal process. The growth mechanism for surfactant-free hydrothermal synthesis of flower-like $\mathrm{ZnO}$ architectures was discussed based on the morphology evolution with reaction time and the effect of the preheating time of precursor solution on their morphologies. The morphology, composition, and crystalline and optical properties of the as-grown flower-like $\mathrm{ZnO}$ architectures were investigated by X-ray diffraction (XRD), field-emission scan electron microscopy (FESEM), high-resolution transmission electron microscopy (HRTEM), and photoluminescence (PL) spectroscopy.

\section{Experimental Details}

All the chemicals were analytic grade reagents and used without further purification. Thin- $\mathrm{ZnO}$ film coated glass slides $(75 \times 25 \times 1 \mathrm{~mm})$ were used as substrates for subsequent growth of flower-like $\mathrm{ZnO}$. $\mathrm{ZnO}$ thin films were grown by pulsed laser ablation of a $\mathrm{ZnO}$ hot pressed disk target (Ceramic, 99.999\%) for $30 \mathrm{~min}$, using the focused output of a KrF laser (Lambda-Physik COMPex 201, $248 \mathrm{~nm}, 5 \mathrm{~Hz}$ repetition rate). Energy used was $250 \mathrm{~mJ} \cdot$ puls $^{-1}$. The target was rotated in order to prevent repeated ablation of the same area. All depositions were conducted in a low background pressure of oxygen $\left(P_{\mathrm{O}}^{2}=10^{-2}\right.$ Torr, $99.99 \%$ stated purity, flowing at 10 standard $\mathrm{cm}^{3} \mathrm{~min}^{-1}(\mathrm{sccm})$ ).

$0.1 \mathrm{M}$ precursor solutions of zinc nitrate hexahydrate $\left(\mathrm{Zn}\left(\mathrm{NO}_{3}\right)_{2} \cdot 6 \mathrm{H}_{2} \mathrm{O}\right)$ and hexamethylenetetramine (HMT) in distilled water $\left(\mathrm{H}_{2} \mathrm{O}\right)$ were prepared, then $100 \mathrm{~mL}$ aliquots of each solution were mixed together in another glass bottle of maximum volume $250 \mathrm{~mL}$, and the bottle was then sealed and heated to $95^{\circ} \mathrm{C}$ and was kept with this temperature 5$24 \mathrm{~h}$, namely, the preheating process. At the end of preheating process, the $\mathrm{ZnO}$ seed layer-coated glass substrates were immersed in the preheated aqueous solution and tilted against the wall of bottle with $\mathrm{ZnO}$ thin films facing down. Subsequently, the bottle was sealed and heated to $95^{\circ} \mathrm{C}$ again for $10 \mathrm{~h}$ without any stirring. The as-grown samples were rinsed in deionized water and then dried in air. Then the asgrown $\mathrm{ZnO}$ samples were annealed at $550^{\circ} \mathrm{C}$ in air and in vacuum atmospheres for $2 \mathrm{~h}$.

The morphology and structure of the samples were characterized by using XRD (Bruker D8 ADVANCE system with $\mathrm{Cu} \mathrm{K} \alpha$ of $1.5406 \AA$ ), field-emission scanning electron microscopy Philips XL30FEG FESEM, and JEOL JEM-2100F HRTEM. The photoluminescence (PL) spectra were recorded at room temperature by $\mathrm{He}-\mathrm{Cd}(325.0 \mathrm{~nm})$ laser excitation.

\section{Results and Discussion}

3.1. Morphology and Structure. Figure 1 shows the FESEM images of $\mathrm{ZnO}$ sample obtained after preheating for $12 \mathrm{~h}$. It can be seen from the low magnification top view FESEM image shown in Figure 1(a) that high density flower-like $\mathrm{ZnO}$ architectures uniformly grow and highly disperse in the substrates without any aggregation, indicating high yield and good uniformity achieved with this fabrication condition. The middle magnification FESEM image in Figure 1(b) shows that each flower has a diameter of about $40-50 \mu \mathrm{m}$ and consists of hundreds of thin curved nanosheets, which are spokewise, projected from a common central zone. As shown in Figures $1(\mathrm{c})$ and $1(\mathrm{~d})$, high magnification FESEM image reveals that these $\mathrm{ZnO}$ nanosheets are about $10-15 \mu \mathrm{m}$ in length, 3-6 $\mu \mathrm{m}$ in width, and about $50 \mathrm{~nm}$ in thickness, which are assembled to form the flower-like architectures. Additionally, low density $\mathrm{ZnO}$ nanorods, as shown in Figure 1(e), can be observed on the space without flower-like $\mathrm{ZnO}$ architectures indicated by the white square in Figure 1(b). Magnified FESEM image clearly reveals that the shape of nanorods is hexagonal prism with a pyramidal top and smooth side surface, as shown in Figure 1(f). The diameter of the $\mathrm{ZnO}$ nanorods is about $100-150 \mathrm{~nm}$; their length is about $1 \mu \mathrm{m}$, and most of the nanorods are perpendicular to the $\mathrm{ZnO}$ coated substrates.

Figure 2(a) shows a typical low resolution TEM image of an individual flower-like $\mathrm{ZnO}$ architecture scraped off from the substrate, which clearly demonstrates that it is made up of projected thin nanosheets. Middle resolution TEM image of an individual $\mathrm{ZnO}$ nanosheet in Figure 2(b) shows that the nanosheets are of good transparency to the electron beam and are homogenous, which indicates that the nanosheets are very thin and their surfaces are very flat, respectively. Two sets of well resolved parallel lattice fringes are observed in high resolution TEM, as shown in Figure 2(c). The interplanar spacing is measured to be $0.52 \mathrm{~nm}$ and $0.28 \mathrm{~nm}$, respectively, corresponding to that of $\{0002\}$ and $\{01-10\}$ planes of $\mathrm{ZnO}$ crystals. Figure $2(\mathrm{~d})$ is its SAED pattern and exhibits visible bright spots corresponding to all the crystal planes of the 


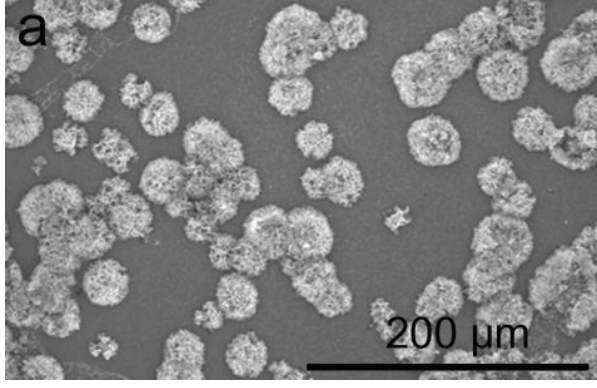

(a)

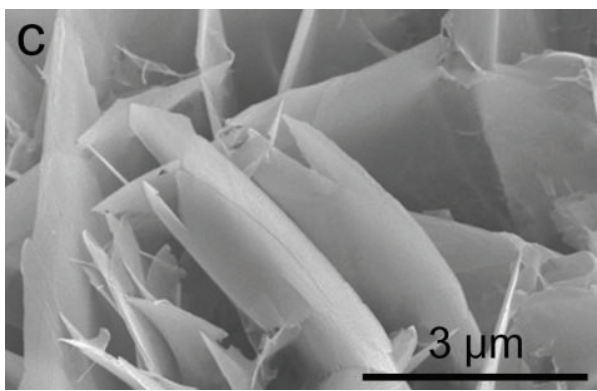

(c)

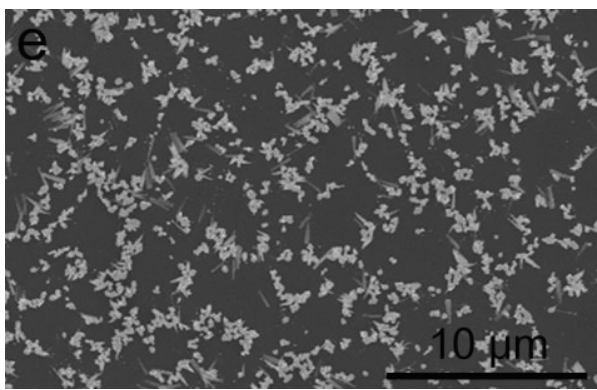

(e)

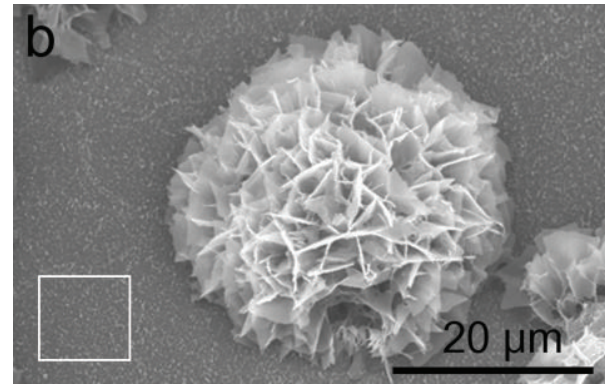

(b)

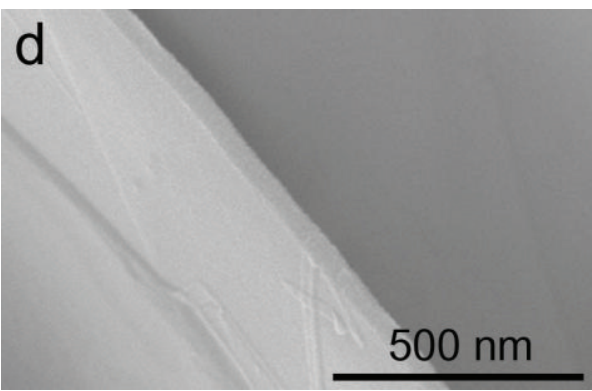

(d)

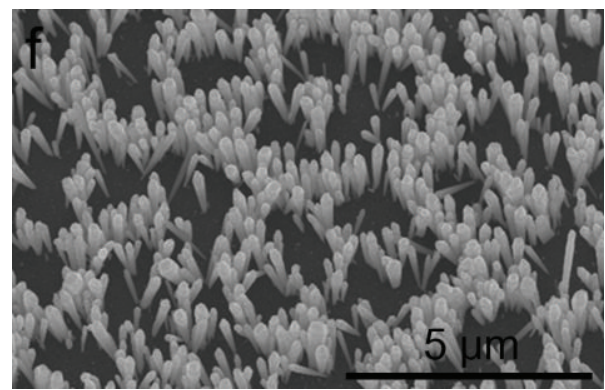

(f)

FIGURE 1: FESEM images of flower-like $\mathrm{ZnO}$ architectures grown on $\mathrm{ZnO}$ thin film coated glass substrates. (a) Low magnification, (b) middle magnification, (c) and (d) high magnification of FESEM images of $\mathrm{ZnO}$ flowers, and (e) and (f) middle magnification of FESEM images from the space without $\mathrm{ZnO}$ flower, as indicated by the white square in (b).

wurtzite $\mathrm{ZnO}$, indicating a single crystalline with a good crystal quality. Based on HRTEM and SAED results, we can thus suggest that the single crystal wurtzite $\mathrm{ZnO}$ nanosheet grows along [0001] and [01-10] crystallographic directions within the (2-1-10) plane.

Figure 3 shows the XRD pattern of the $\mathrm{ZnO}$ sample scraped from the substrates to eliminate the influence of $\mathrm{ZnO}$ seed layer. Three diffraction peaks in the pattern can be indexed as the hexagonal $\mathrm{ZnO}$ with lattice constants $a=3.249$ and $c=5.206 \AA$, consistent with the values in the standard card (JCPDS 36-1451). An energy dispersive spectroscopy (EDS) of flower-like $\mathrm{ZnO}$, as shown in Figure 4, contains only elements of $\mathrm{Zn}$ and $\mathrm{O}$, without any other impurity contamination in the sample.

3.2. Morphology Evolution with Growth Time. To understand how the flower-like $\mathrm{ZnO}$ architectures are formed, the growth time dependent morphological evolution process was examined by FESEM. Figures 5(a)-5(d) show the morphologies of the flower-like $\mathrm{ZnO}$ architectures with different growth times after the growth solution was preheated for $12 \mathrm{~h}$. Figure 5(a) reveals that only $\mathrm{ZnO}$ nanorods are observed after $2 \mathrm{~h}$. A careful examination shows that these $\mathrm{ZnO}$ nanorods are $80 \mathrm{~nm}$ in diameter and $500 \mathrm{~nm}$ in length. When the reaction time increased up to $4 \mathrm{~h}$, a quasisphere nanostructure with a diameter of 4-5 $\mu \mathrm{m}$ emerged over the top of $\mathrm{ZnO}$ nanorods, which is aggregated from numerous small-size nanosheets with $20 \mathrm{~nm}$ in thickness, as shown in Figure 5(b). When the reaction time was prolonged to $6 \mathrm{~h}$, some nanosheets with large length and width extend from the quasisphere center to outside, assembling into flower-like structures as a whole, as displayed in Figure 5(c). After $9 \mathrm{~h}$, the nanosheets became bigger and longer and began to connect to each other, forming a complete flower-like structure, as shown in Figure 1(b). All the nanosheets are joined to each other through basic quasisphere center in such a manner that the flower exhibits a spherical shape. When the growth time was prolonged further to $24 \mathrm{~h}$, the flower-like $\mathrm{ZnO}$ 


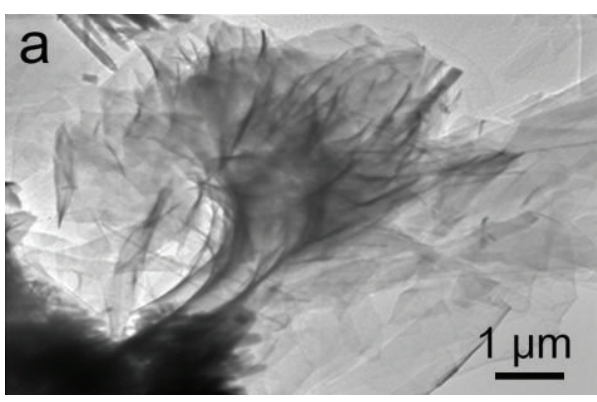

(a)

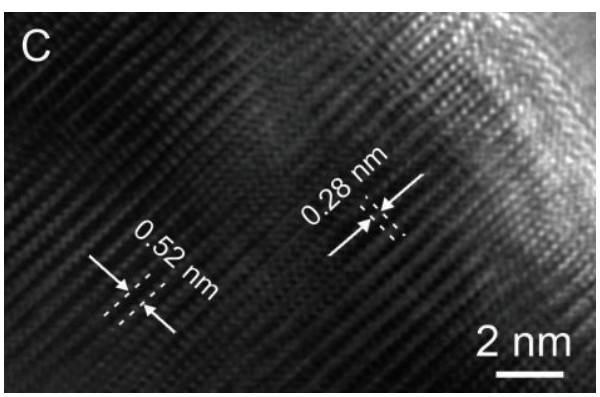

(c)

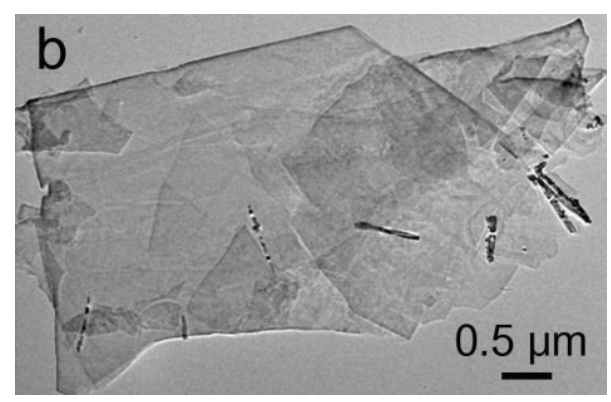

(b)

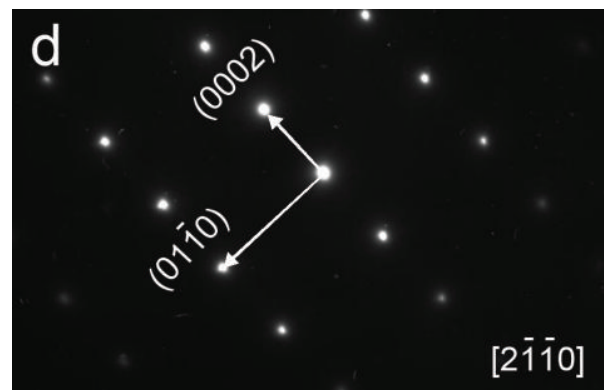

(d)

FIgURE 2: TEM images of flower-like $\mathrm{ZnO}$ architectures. Typical TEM images of (a) an individual $\mathrm{ZnO}$ flower and (b) a piece of $\mathrm{ZnO}$ nanosheet. (c) HRTEM image and (d) SAED image of a piece of $\mathrm{ZnO}$ nanosheet.

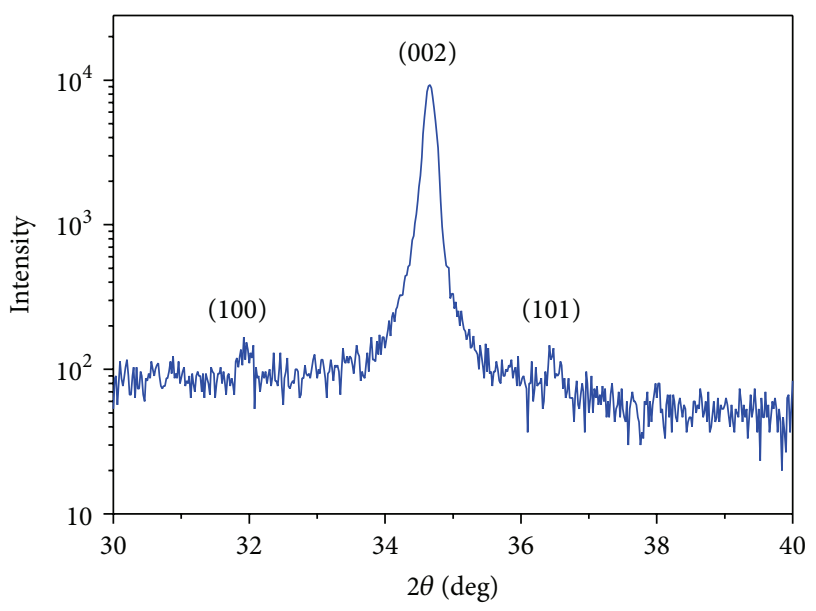

FIGURE 3: XRD pattern of flower-like $\mathrm{ZnO}$ architectures.

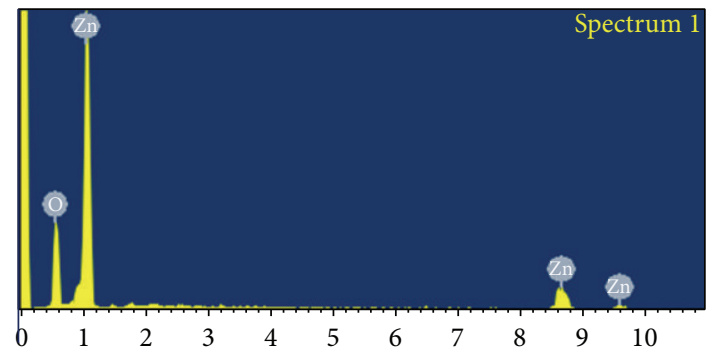

FIGURE 4: The EDS spectrum corresponds to the flower-like $\mathrm{ZnO}$ nanostructures. nanostructures are aggregated and mingled in each other and form network-shaped nanosheet films, which do not exhibit clear ordered patterns, as shown in Figure 5(d).

3.3. Morphology Evolution with Preheating Time. Further experiments indicate that the preheating time is crucial for the formation of such complex $\mathrm{ZnO}$ architectures. Figure 6 exhibits the morphologies of the products with different preheating times when other experimental conditions keep unchanged. Without preheating process, only nearly vertically arranged nanorod arrays are formed on the $\mathrm{ZnO}$ seed layer-coated substrates, as shown in Figure 6(a), which are $120 \mathrm{~nm}$ in the diameter and $2 \mu \mathrm{m}$ in the length after growing for $10 \mathrm{~h}$. The same results have been extensively reported $[28,29]$. After preheating for $7 \mathrm{~h}$, ultralong $\mathrm{ZnO}$ nanowires with honeycomb-like micropatterns (indicated by dotted line) could be observed from the overview image as shown in Figure 6(b). Such honeycomb-like micropatterns consisting of ultralong $\mathrm{ZnO}$ nanowires are similar to the one described by $\mathrm{Lu}$ et. al. [49-51]. A magnified FESEM image shown in Figure 5(c) shows that the nanowires are of high aspect ratio (>200), with the diameter of $50 \mathrm{~nm}$ and the length of up to $10 \mu \mathrm{m}$. A higher magnification FESEM image of the $\mathrm{ZnO}$ nanowire roots reveals that $\mathrm{ZnO}$ nanowires also selectively grow from $\mathrm{ZnO}$ nanorod arrays, as shown in the inset of Figure 6(c). A further increase in preheating time to $12 \mathrm{~h}$ gives rise to a flower-like $\mathrm{ZnO}$ architecture, as shown in Figure 1(b). However, if preheating time is too long, for example, more than $24 \mathrm{~h}$, nothing can be observed from the substrates. These results indicate that flower-like $\mathrm{ZnO}$ architectures can only be synthesized in a suitable preheating time of about $12 \mathrm{~h}$. 


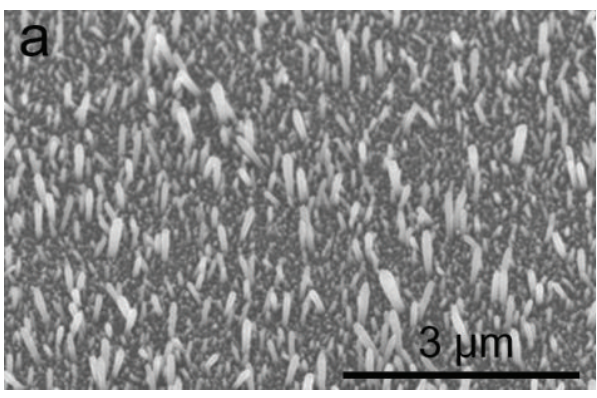

(a)

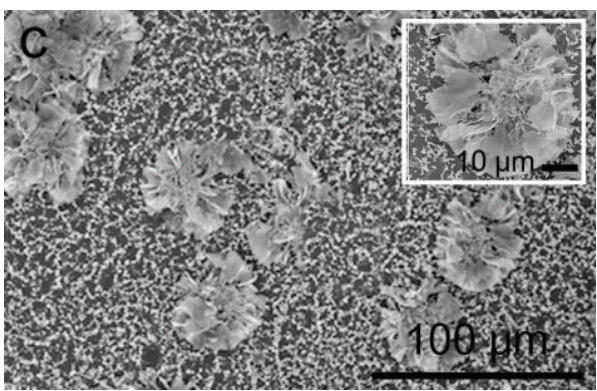

(c)

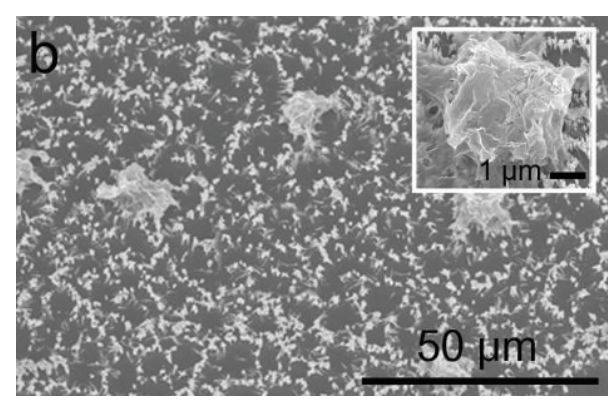

(b)

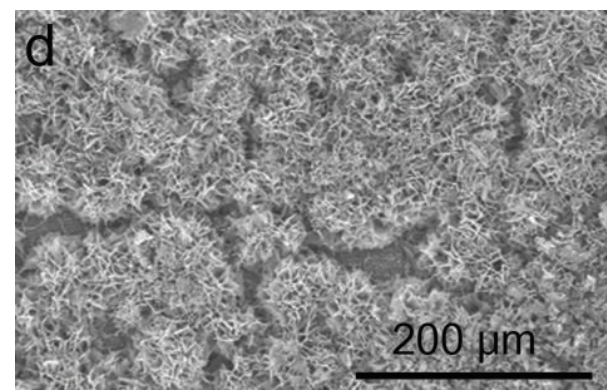

(d)

Figure 5: The morphology evolution of flower-like $\mathrm{ZnO}$ architectures depends on the growth time: (a) $2 \mathrm{~h}$, (b) $4 \mathrm{~h}$, (c) $6 \mathrm{~h}$, and (d) $24 \mathrm{~h}$.

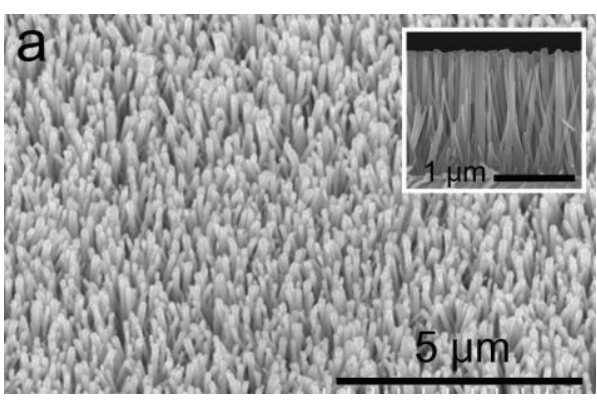

(a)

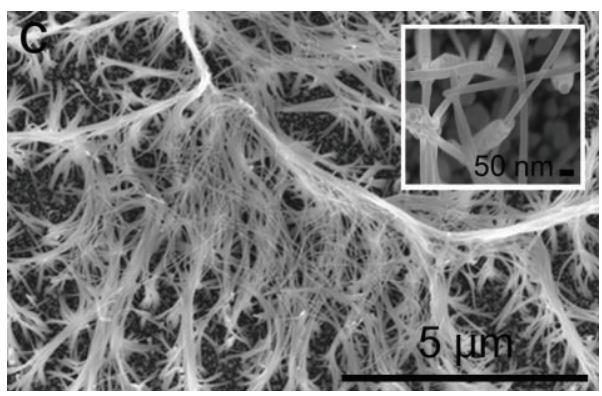

(c)

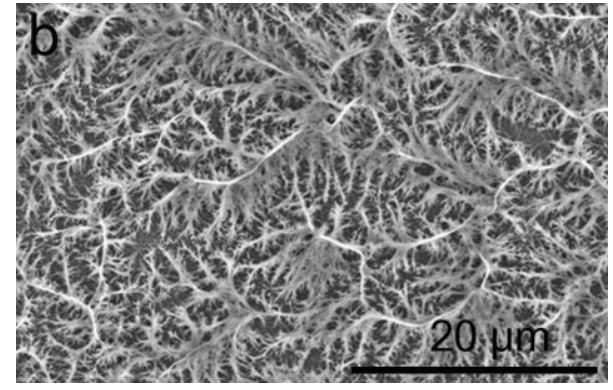

(b)

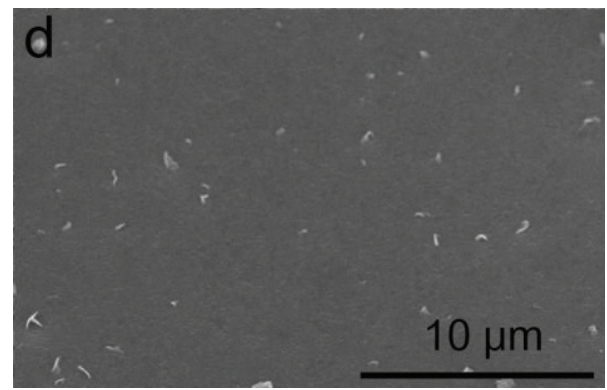

(d)

FIGURE 6: FESEM images of samples after different preheating time at $95^{\circ} \mathrm{C}$ : (a) without preheating, (b) and (c) $7 \mathrm{~h}$, and (d) $24 \mathrm{~h}$.

In addition, nothing can be synthesized on the bare glass substrate without a $\mathrm{ZnO}$ seed layer on its surface, indicating $\mathrm{ZnO}$ seed layer is also favorable for the formation of nanosheet flower-like architecture.

3.4. Formation Mechanism. The flower-like $\mathrm{ZnO}$ growth process is summarized in Figure 7. In our study, $\mathrm{Zn}^{2+}$ and $\mathrm{OH}^{-}$are provided by hydration of $\mathrm{Zn}\left(\mathrm{NO}_{3}\right)_{2}$ and HMT, respectively. Therefore, the key chemical reactions can be formulated as follows:

$$
\begin{gathered}
\left(\mathrm{CH}_{2}\right)_{6} \mathrm{~N}_{4}+\mathrm{H}_{2} \mathrm{O} \stackrel{\Delta}{\rightarrow} 4 \mathrm{NH}_{3(\mathrm{~g})}+6 \mathrm{HCHO}_{(\mathrm{g})} \\
\mathrm{NH}_{3}+\mathrm{H}_{2} \mathrm{O} \longrightarrow \mathrm{NH}_{4}^{+}+\mathrm{OH}^{-} \\
\mathrm{Zn}^{2+}+2 \mathrm{OH}^{-} \longrightarrow \mathrm{Zn}(\mathrm{OH})_{2(\mathrm{~s})} \\
\mathrm{Zn}(\mathrm{OH})_{2} \stackrel{\Delta}{\rightarrow} \mathrm{ZnO}_{(\mathrm{s})}+\mathrm{H}_{2} \mathrm{O}
\end{gathered}
$$




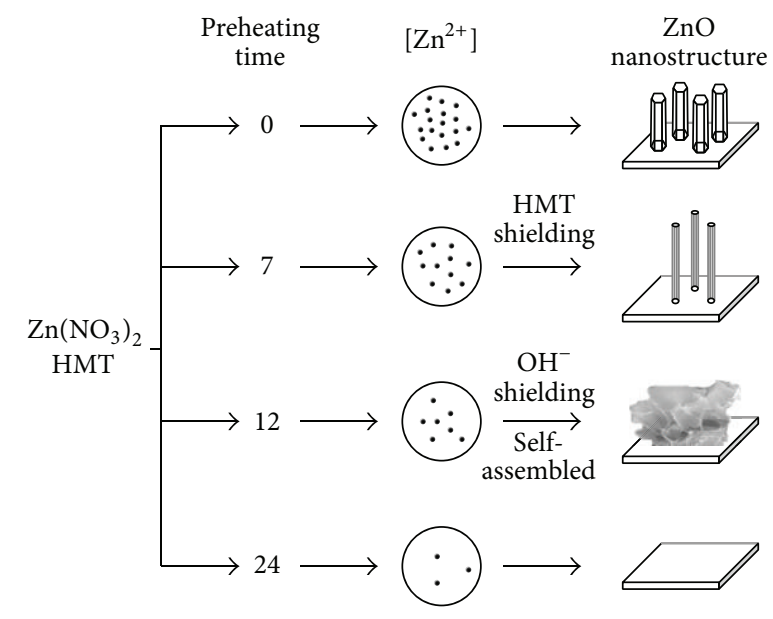

FIGURE 7: Schematic growth diagram of the $\mathrm{ZnO}$ nanostructures fabricated by preheating hydrothermal method.

Generally, the typical growth direction of $\mathrm{ZnO}$ crystal is along the [0001] direction due to the higher growth rate compared to other growth facets [50,52-54]; thus, nanorod or nanowires type morphologies are obtained often. Considering the crystal growth in liquid medium, although the crystal growth habit is mainly determined by the intrinsic structure, it is also affected by the external conditions such as organic surfactants, $\mathrm{pH}$ of solution, saturation, and temperature. For example, the organic surfactants can change the surface free energy of different $\mathrm{ZnO}$ crystal faces, adjust the growth rates of various crystal planes, and control their preferential growth or elimination, leading to various crystal structures and morphologies.

In this work, three factors are considered to play a key role in the formation of nanosheet based flower-like $\mathrm{ZnO}$ architectures, the concentration of zinc, $\mathrm{pH}$ value of growth solution, and $\mathrm{ZnO}$ seed layer. In the whole hydrothermal process, the $\mathrm{Zn}^{2+}$ concentration linearly decreases with preheating and growth time due to the formation of $\mathrm{ZnO}$ crystal precipitates. However, $\mathrm{pH}$ of the solution nearly keeps constant because HMT acts as not only a source of $\mathrm{OH}^{-}$to drive the precipitation reaction, but also a $\mathrm{pH}$ buffer to slow release of $\mathrm{OH}^{-}$by reactions 1 and 2 [5557]. Without preheating, high zinc ion concentration benefits the formation of $\mathrm{ZnO}$ nanorods with small aspect ratio. This can be further demonstrated from the fact that the diameter of $\mathrm{ZnO}$ nanorod increases with increasing the zinc concentration. After preheating process for $7 \mathrm{~h}$, the $\mathrm{ZnO}$ nanorods or nanowires with small diameter and high aspect ratio can be obtained due to the dissolution-regrowth and transport limiting in the solution and the shielding effect of HMT [58-61]. With increasing preheating time, partial $\mathrm{ZnO}$ nanorods will be decomposed into zinc ions again because of the consumption of the zinc ions in solution. In our case, the dissolution of six crystallographic nonpolar $\{01-10\}$ planes was accelerated due to small diameter and high contact interface with precursor solution. At the same time, the decomposed zinc ions directly transfer to the vicinal polar Zn-terminated (0001) planes with high chemicalactive. Then it results in the decreasing of the diameter and the quick increase of length and aspect ratio. Additionally, residual hexamine after preheating process, being a nonpolar chelating agent, would preferentially attach to the nonpolar facets of the $\mathrm{ZnO}$ nanorods/wires, thereby exposing only the polar Zn-terminated (0001) plane for epitaxial growth, which also promotes the growth along [0001] direction and drives the formation of small-size $\mathrm{ZnO}$ nanowires. After preheating was further increased to $12 \mathrm{~h}$, zinc concentration further decreases into a suitable value; the growth rates of nonpolar (2-1-10) and nonpolar (01-10) planes are largely enhanced due to lower surface energy compared to that of polar (0001) plane. Simultaneously, the consumption of HMT weakens the shielding effect of HMT. On the contrary, the superfluous $\mathrm{OH}^{-}$ions are easily adsorbed on the positively charged (0001) Zn-terminated surface and the growth rates along [01-10] and [2-1-10] directions are enhanced to a certain extent due to the shielding effect of $\mathrm{OH}^{-}$ions on the (0001) surface [62]. As a result, the highest growth rate along the [0001] direction and the larger growth facets of (2-1-10) and (01-10) result in the formation of $\mathrm{ZnO}$ nanosheets.

The formation of flower-like $\mathrm{ZnO}$ architectures was achieved via a self-assembly process. From the thermodynamics point of view, the surface energy of an individual nanosheet is quite high with two main exposed planes, and thus they tend to aggregate to decrease the surface energy by reducing exposed areas. The surface energy is substantially reduced after the neighboring nanosheets are self-assembled. Additionally, the long range electrostatic interactions among the polar charges of $\{0001\}$ planes also can induce selfassembly process. As a result, flower-like $\mathrm{ZnO}$ architectures assembled from nanosheets building blocks are constructed by this self-assembly process.

After preheating for $12 \mathrm{~h}$, the degree of supersaturation of growth precursor is too low to heterogeneously nucleate on the substrates due to lattice mismatch. However, the presence of the $\mathrm{ZnO}$ seed layer can effectively lower the nucleation energy barrier, and homogeneous nucleation easily occurs on the seed layer, are benefit to the growth of nanorods and nanosheets.

3.5. Optical Properties. Figure 8 shows the room temperature $\mathrm{PL}$ spectra of flower-like ZnO architectures. The PL spectrum is featured by a peak near the ultraviolet region (UV) and a peak related to defects in the visible region (VIS). Through Gaussian fitting, the UV PL centered at $400 \mathrm{~nm}$ can be fitted well by two peaks centered at 383 and $410 \mathrm{~nm}$, as shown by the dash dot line in Figure 8. The emission at $383 \mathrm{~nm}$ originated from the free excitonic recombination, which can be observed at room temperature due to the large exciton binding energy of $\mathrm{ZnO}$ (about $60 \mathrm{meV}$ ). It has been reported that thermal energy at room temperature may be enough to release bound excitons because the binding energy of bound excitons is only a few millielectron volts $[62,63]$. The violet emission at $410 \mathrm{~nm}$, which has been frequently observed in glass substrates, is commonly attributed to the oxygen dangling 


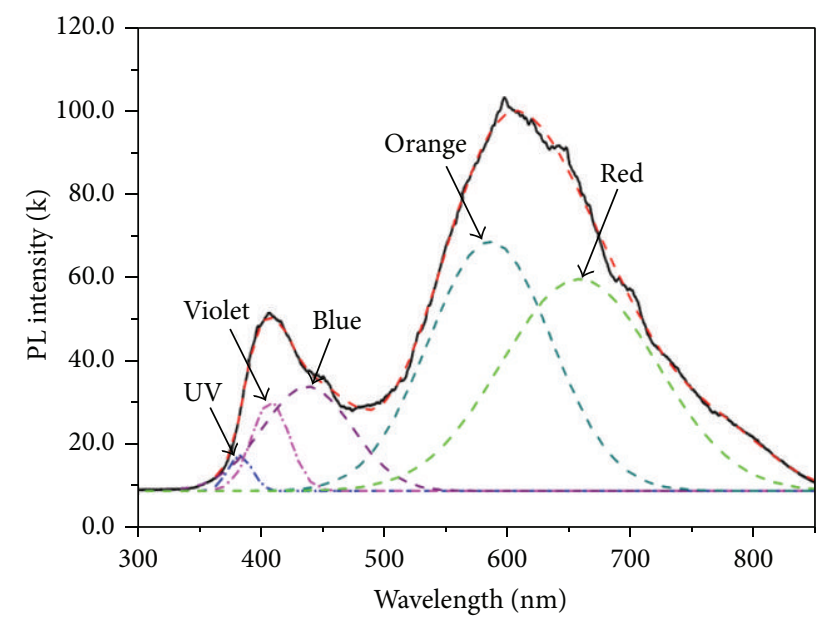

FIGURE 8: Room temperature PL spectra of as-grown flower-like $\mathrm{ZnO}$ architectures.

bonds on the glass surface or the interface between glass substrate and $\mathrm{ZnO}$ nanostructures [64, 65]. Additionally, a large number of irradiative defects related to the traps existing at the nanosheet boundaries possibly contribute to the violet emission due to the transition between this level and the valence band $[66,67]$. Although the presence of cubic $\mathrm{ZnO}$, which might exist near the glass substrate interface, can be considered as a possible origin for this emission in the light of Sekiguchi's report [68], this cannot explain the emission in our case, because there is no evidence for the existence of cubic $\mathrm{ZnO}$ from the XRD analysis.

The strong VIS-PL is fitted well by three Gaussians with a weak blue peak located at $450 \mathrm{~nm}$, a strong orange peak centered at $603 \mathrm{~nm}$, and a red shoulder at $715 \mathrm{~nm}$, as shown by the dash lines in Figure 8 . The blue emission was reported in tetrapodal nanocrystals $[69,70]$ and is often attributed to oxygen vacancies [69-74] or zinc vacancies [75]. Fu et al. [76] and Janotti and van de Walle [67] thought that the oxygen vacancy is a shallow intrinsic donor in $\mathrm{ZnO}$ and zinc vacancies form the deep acceptor level. They deduced that the blue emission included two transitions of electrons: from the shallow donor of oxygen vacancies to the valence band or from the conduction band to the acceptor of zinc vacancies. Other hypotheses include zinc interstitials, which were proposed by Zhang et al. [74], based on the band structure calculations. They deemed that the blue emission may correspond to the electron transition from the shallow donor level of zinc interstitials to the valence band or to the acceptor energy level of zinc vacancies.

The orange emission is also reported in $\mathrm{ZnO}$ nanostructures, and it represents a common feature in samples prepared by electrochemically [77], hydrothermally [68], and spray pyrolysis methods [78]. The orange emission is commonly attributed to oxygen interstitials, which is supported by the reports of decreasing or vanishing of orange peak after annealing under vacuum or in a $\mathrm{H}_{2} / \mathrm{Ar}$ mixture $[79,80]$. In addition to this common hypothesis, the possible presence of $\mathrm{Zn}(\mathrm{OH})_{2}$ or hydroxyl groups $\left(\mathrm{OH}^{-}\right)$at the surface was

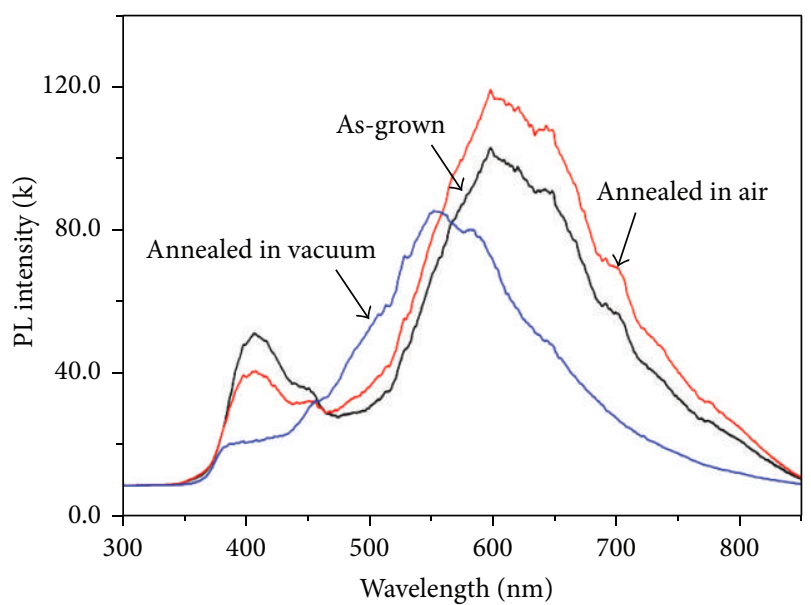

FIGURE 9: Room temperature PL spectrum of flower-like $\mathrm{ZnO}$ architectures after annealing at different atmospheres at $550^{\circ} \mathrm{C}$ for $2 \mathrm{~h}$.

identified as a possible origin of the orange emission at $600 \mathrm{~nm}$ [81-83].

Although most of the studies attribute the origin of red emission to excess oxygen interstitials $[84,85]$, recently zincrelated defects were also proposed as an original of a red emission $[82,84,86]$. Further studies are needed to clarify the origin of the red emission.

In order to investigate the nature of the VLS-PL in the asgrown sample, a series of annealing experiments were undertaken involving both ambient and vacuum environment, and the results were shown in Figure 9.

The PL spectrum of the sample after annealing in air at $550^{\circ} \mathrm{C}$ for $2 \mathrm{~h}$ is shown in Figure 9. The position of the orange emission has changed a little and its intensity slightly increased, indicating that orange emission is not due to $\mathrm{Zn}(\mathrm{OH})_{2}$ or hydroxyl groups $\left(\mathrm{OH}^{-}\right)$at the surface, because their concentrations obviously decrease after annealing at rich oxygen atmosphere due to desorption $[82,83]$, resulting in reduction in orange emission intensity. However, a strong green emission is observed after annealing in vacuum at $550^{\circ} \mathrm{C}$ for $2 \mathrm{~h}$. The green emission centered at $540 \mathrm{~nm}$, commonly seen in $\mathrm{ZnO}$ structures synthesized from oxygendeficient conditions, is often attributed to the recombination of electrons and holes in singly ionized oxygen vacancies [86-91] and could be quenched or red-shifted after annealing in oxygen-rich atmosphere. These results suggest that the orange emission in as-grown sample is mainly attributed to oxygen-related defects. However, no evidence of a green emission and no apparent red-shift make a possibility of existing oxygen vacancies in as-grown flower-like $\mathrm{ZnO}$ structures nearly zero. Therefore, it could be concluded that the asgrown flower-like $\mathrm{ZnO}$ nanostructures are oxygen-rich, and the orange emission centered at $600 \mathrm{~nm}$ can be attributed to only oxygen interstitials, in agreement with a previous study on $\mathrm{ZnO}$ films [92] and $\mathrm{ZnO}$ nanorod arrays [77].

Due to absence of oxygen vacancies in oxygen-rich asgrown flower-like $\mathrm{ZnO}$ nanostructures, only zinc related defects can be used to explain the origin of the blue emission 
at $440 \mathrm{~nm}$. Based on the defect energy levels calculated by Sun and others [93-95] using full-potential linear muffin-tin orbital method, the energy interval from the donor level of zinc interstitial $\left(\mathrm{Zn}_{i}{ }^{\prime \prime}\right)$ to the top of the valence band $(2.9 \mathrm{eV})$ and to the acceptor level of zinc vacancies $(2.6 \mathrm{eV})$ is close to the energy of the blue emission $(2.8 \mathrm{eV})$ observed in our case. But the possibility of forming zinc vacancies is little because the enthalpy of defect $(\Delta H)$ is $7 \mathrm{eV}$. Therefore, we believe that the transition of electrons from zinc interstitials to the valence band dominates the blue emission. After annealing, the intensity of blue emission decreases because the concentration of zinc interstitials decreases due to the diffusion [79, 96] and evaporation [70] of zinc interstitials resulted from a relatively high mobility.

Both oxygen interstitial and zinc interstitial defects in the as-grown flower-like $\mathrm{ZnO}$ architectures can be related to the red emission. The enhancement of red emission after annealing in air and its disappearance after annealing in vacuum apparently indicate that mechanism of the red emission is related to defects associated with excess oxygen. On the other hand, if the red emission was caused by zinc interstitials, the violet emission derived from zinc interstitial defects will be quenched or vanished with the disappearance of the red emission after annealing in vacuum, which disagreed with the result shown in Figure 9, indicating that zinc interstitial defects are not dominated origin for red emission in our case.

\section{Conclusions}

The flower-like $\mathrm{ZnO}$ architectures with a diameter of 40$50 \mu \mathrm{m}$, which consist of large numbers of thin and uniform hexagonal-structured $\mathrm{ZnO}$ nanosheets with a thickness of $40-50 \mathrm{~nm}$, have been synthesized by using preheating hydrothermal method without any additives. The morphology of $\mathrm{ZnO}$ transforms from nanorod to nanosheets with increasing the preheating time and a low concentration of zinc ions in precursor solution after preheating for $12 \mathrm{~h}$ was proved to be a crucial factor in the formation of $\mathrm{ZnO}$ nanosheets blocks and flower-like architectures. Room temperature PL spectra results show that strong visible emission in the orange-red range in as-grown sample is replaced by green emission peak with a lower intensity after annealing in vacuum at $550^{\circ} \mathrm{C}$ for $2 \mathrm{~h}$. The blue-shift of visible emission peak indicates that the position and intensity of orange-red peak can be strongly affected by annealing atmosphere and likely originates from intrinsic and surface defects, especially oxygen interstitials.

\section{Conflict of Interests}

The authors declare that there is no conflict of interests regarding the publication of this paper.

\section{Acknowledgments}

This work was supported by the Korea Research Foundation Grants (KRF-2006-005-J02802 and KRF-2006-005-J02803). This work was also supported by the Korea Science and
Engineering Foundation (KOSEF, R01-000-20757-0) Grant funded by the Korean government.

\section{References}

[1] Z. Ding, B. M. Quinn, S. K. Haram, L. E. Pell, B. A. Korgel, and A. J. Bard, "Electrochemistry and electrogenerated chemiluminescence from silicon nanocrystal quantum dots," Science, vol. 296, no. 5571, pp. 1293-1297, 2002.

[2] A. P. Alivisatos, "Semiconductor clusters, nanocrystals, and quantum dots," Science, vol. 271, no. 5251, pp. 933-937, 1996.

[3] Z. L. Wang, X. Y. Kong, Y. Ding et al., "Semiconducting and piezoelectric oxide nanostructures induced by polar surfaces," Advanced Functional Materials, vol. 14, no. 10, pp. 943-956, 2004.

[4] G. Ren, Z. Lin, B. Gilbert, J. Zhang, F. Huang, and J. Liang, "Evolution of $\mathrm{ZnS}$ nanostructure morphology under interfacial free-energy control," Chemistry of Materials, vol. 20, no. 7, pp. 2438-2443, 2008.

[5] M. J. Zheng, L. D. Zhang, G. H. Li, and W. Z. Shen, "Fabrication and optical properties of large-scale uniform zinc oxide nanowire arrays by one-step electrochemical deposition technique," Chemical Physics Letters, vol. 363, no. 1-2, pp. 123128, 2002.

[6] L. Vayssieres, K. Keis, A. Hagfeldt, and S. E. Lindquist, “Threedimensional array of highly oriented crystalline $\mathrm{ZnO}$ microtubes," Chemistry of Materials, vol. 13, no. 12, pp. 4395-4398, 2001.

[7] J. Y. Lao, J. Y. Huang, D. Z. Wang, and Z. F. Ren, " $\mathrm{ZnO}$ nanobridges and nanonails," Nano Letters, vol. 3, no. 2, pp. 235238, 2003.

[8] D. F. Liu, Y. J. Xiang, Z. X. Zhang et al., "Growth of $\mathrm{ZnO}$ hexagonal nanoprisms," Nanotechnology, vol. 16, no. 11, pp. 2665-2669, 2005.

[9] J. Q. Hu, Q. Li, X. M. Meng, C. S. Lee, and S. T. Lee, "Thermal reduction route to the fabrication of coaxial $\mathrm{Zn} / \mathrm{ZnO}$ nanocables and $\mathrm{ZnO}$ nanotubes," Chemistry of Materials, vol. 15, no. 1, pp. 305-308, 2003.

[10] X. Y. Kong, Y. Ding, R. Yang, and Z. L. Wang, "Single-Crystal nanorings formed by epitaxial self-coiling of polar nanobelts," Science, vol. 303, no. 5662, pp. 1348-1351, 2004.

[11] J. Q. Hu and Y. Bando, "Growth and optical properties of singlecrystal tubular ZnO whiskers," Applied Physics Letters, vol. 82, no. 9, pp. 1401-1403, 2003.

[12] C. S. Lao, P. X. Gao, R. S. Yang, Y. Zhang, Y. Dai, and Z. L. Wang, "Formation of double-side teethed nanocombs of $\mathrm{ZnO}$ and self-catalysis of Zn-terminated polar surface," Chemical Physics Letters, vol. 417, pp. 359-363, 2005.

[13] J. X. Wang, X. W. Sun, A. Wei et al., "Zinc oxide nanocomb biosensor for glucose detection," Applied Physics Letters, vol. 88, no. 23, Article ID 233106, 2006.

[14] X. Y. Kong and Z. L. Wang, "Spontaneous polarizationinduced nanohelixes, nanosprings, and nanorings of piezoelectric nanobelts," Nano Letters, vol. 3, no. 12, pp. 1625-1631, 2003.

[15] P. X. Gao and Z. L. Wang, "Nanopropeller arrays of zinc oxide," Applied Physics Letters, vol. 84, no. 15, pp. 2883-2885, 2004.

[16] W. L. Hughes and Z. L. Wang, "Formation of piezoelectric single-crystal nanorings and nanobows," Journal of the American Chemical Society, vol. 126, no. 21, pp. 6703-6709, 2004.

[17] P. X. Gao and Z. L. Wang, "Mesoporous polyhedral cages and shells formed by textured self-assembly of $\mathrm{ZnO}$ nanocrystals," 
Journal of the American Chemical Society, vol. 125, no. 37, pp. 11299-11305, 2003.

[18] C. X. Xu, X. W. Sun, Z. L. Dong, and M. B. Yu, "Zinc oxide nanodisk," Applied Physics Letters, vol. 85, no. 17, pp. 3878-3880, 2004.

[19] C. X. Xu and X. W. Sun, "Field emission from zinc oxide nanopins," Applied Physics Letters, vol. 83, no. 18, pp. 3806-3808, 2003.

[20] G. Q. Ding, W. Z. Shen, M. J. Zheng, and D. H. Fan, "Synthesis of ordered large-scale $\mathrm{ZnO}$ nanopore arrays," Applied Physics Letters, vol. 88, no. 10, Article ID 103106, 2006.

[21] X. H. Zhang, Y. C. Liu, X. H. Wang et al., "Structural properties and photoluminescence of $\mathrm{ZnO}$ nanowalls prepared by two-step growth with oxygen-plasma-assisted molecular beam epitaxy," Journal of Physics Condensed Matter, vol. 17, no. 19, pp. 3035-3042, 2005.

[22] J. Y. Park, Y. S. Yun, Y. S. Hong, H. Oh, J.-J. Kim, and S. S. Kim, "Synthesis, electrical and photoresponse properties of vertically well-aligned and epitaxial $\mathrm{ZnO}$ nanorods on $\mathrm{GaN}$ buffered sapphire substrates," Applied Physics Letters, vol. 87, no. 12, Article ID 123108, pp. 1-3, 2005.

[23] M. T. Chen and J. M. Ting, "Sputter deposition of $\mathrm{ZnO}$ nanorods/thin-film structures on Si," Thin Solid Films, vol. 494, no. 1-2, pp. 250-254, 2006.

[24] Y. Sun and M. N. R. Ashfold, "Photoluminescence from diameter-selected ZnO nanorod arrays," Nanotechnology, vol. 18, no. 24, Article ID 245701, 2007.

[25] Y. B. Li, Y. Bando, T. Sato, and K. Kurashima, "ZnO nanobelts grown on Si substrate," Applied Physics Letters, vol. 81, no. 1, pp. 144-146, 2002.

[26] B. D. Yao, Y. F. Chan, and N. Wang, "Formation of $\mathrm{ZnO}$ nanostructures by a simple way of thermal evaporation," Applied Physics Letters, vol. 81, no. 4, pp. 757-759, 2002.

[27] Z. W. Pan, Z. R. Dai, and Z. L. Wang, "Nanobelts of semiconducting oxides," Science, vol. 291, no. 5510, pp. 1947-1949, 2001.

[28] Q. Li, V. Kumar, Y. Li, H. Zhang, T. J. Marks, and R. P. $\mathrm{H}$. Chang, "Fabrication of $\mathrm{ZnO}$ nanorods and nanotubes in aqueous solutions," Chemistry of Materials, vol. 17, no. 5, pp. 1001-1006, 2005.

[29] R. B. Peterson, C. L. Fields, and B. A. Gregg, "Epitaxial chemical deposition of $\mathrm{ZnO}$ nanocolumns from $\mathrm{NaOH}$ solutions," Langmuir, vol. 20, no. 12, pp. 5114-5118, 2004.

[30] J. Yang, G. Liu, J. Lu, Y. Qiu, and S. Yang, "Electrochemical route to the synthesis of ultrathin $\mathrm{ZnO}$ nanorod/nanobelt arrays on zinc substrate," Applied Physics Letters, vol. 90, no. 10, Article ID 103109, 2007.

[31] H. Gao, F. Yan, J. Li, Y. Zeng, and J. Wang, "Synthesis and characterization of $\mathrm{ZnO}$ nanorods and nanoflowers grown on GaN-based LED epiwafer using a solution deposition method," Journal of Physics D: Applied Physics, vol. 40, no. 12, pp. 36543659, 2007.

[32] W. Zhao, X. Song, Z. Yin, C. Fan, G. Chen, and S. Sun, "Self-assembly of $\mathrm{ZnO}$ nanosheets into nanoflowers at room temperature," Materials Research Bulletin, vol. 43, no. 11, pp. 3171-3176, 2008.

[33] H. Zhang, D. Yang, X. Ma, Y. Ji, J. Xu, and D. Que, "Synthesis of flower-like $\mathrm{ZnO}$ nanostructures by an organic-free hydrothermal process," Nanotechnology, vol. 15, no. 5, pp. 622-626, 2004.

[34] S. Yu, C. Wang, J. Yu, W. Shi, R. Deng, and H. Zhang, "Precursor induced synthesis of hierarchical nanostructured ZnO," Nanotechnology, vol. 17, pp. 3607-3612, 2006.
[35] Z. R. Tian, J. A. Voigt, J. Liu, B. Mckenzie, and M. J. Mcdermott, "Biomimetic arrays of oriented helical $\mathrm{ZnO}$ nanorods and columns," Journal of the American Chemical Society, vol. 124, no. 44, pp. 12954-12955, 2002.

[36] T. Zhang, W. Dong, M. Keeter-Brewer, S. Konar, R. N. Njabon, and Z. R. Tian, "Site-specific nucleation and growth kinetics in hierarchical nanosyntheses of branched $\mathrm{ZnO}$ crystallites," Journal of the American Chemical Society, vol. 128, no. 33, pp. 10960-10968, 2006.

[37] T. L. Sounart, J. Liu, J. A. Voigt, M. Huo, E. D. Spoerke, and B. McKenzie, "Secondary nucleation and growth of $\mathrm{ZnO}$," Journal of the American Chemical Society, vol. 129, no. 51, pp. 1578615793, 2007.

[38] T. L. Sounart, J. Liu, J. A. Voigt et al., "Sequential nucleation and growth of complex nanostructured films," Advanced Functional Materials, vol. 16, no. 3, pp. 335-344, 2006.

[39] B. Liu and C. Z. Hua, "Fabrication of $\mathrm{ZnO}$ "Dandelions" via a modified Kirkendall process," Journal of the American Chemical Society, vol. 126, no. 51, pp. 16744-16746, 2004.

[40] S. Gao, H. Zhang, X. Wang, R. Deng, D. Sun, and G. Zheng, "ZnO-based hollow microspheres: biopolymer-assisted assemblies from ZnO nanorods," Journal of Physical Chemistry B, vol. 110, no. 32, pp. 15847-15852, 2006.

[41] Y. F. Zhu, D. H. Fan, and W. Z. Shen, "Template-free synthesis of zinc oxide hollow microspheres in aqueous solution at low temperature," The Journal of Physical Chemistry C, vol. 111, no. 50, pp. 18629-18635, 2007.

[42] H. P. Cong and S. H. Yu, "Hybrid ZnO-dye hollow spheres with new optical properties from a self-assembly process based on evans blue dye and cetyltrimethylammonium bromide," Advanced Functional Materials, vol. 17, no. 11, pp. 1814-1820, 2007.

[43] C.-L. Kuo, T.-J. Kuo, and M. H. Huang, "Hydrothermal synthesis of $\mathrm{ZnO}$ microspheres and hexagonal microrods with sheetlike and platelike nanostructures," The Journal of Physical Chemistry B, vol. 109, no. 43, pp. 20115-20121, 2005.

[44] H. Li, Y. Ni, and J. Hong, "Ultrasound-assisted preparation, characterization and properties of flower-like $\mathrm{ZnO}$ microstructures," Scripta Materialia, vol. 60, no. 7, pp. 524-527, 2009.

[45] Q. Ahsanulhaq, S. H. Kim, J. H. Kim, and Y. B. Hahn, "Structural properties and growth mechanism of flower-like $\mathrm{ZnO}$ structures obtained by simple solution method," Materials Research Bulletin, vol. 43, no. 12, pp. 3483-3489, 2008.

[46] J. Liu, X. Huang, Y. Li, J. Duan, and H. Ai, "Large-scale synthesis of flower-like $\mathrm{ZnO}$ structures by a surfactant-free and lowtemperature process," Materials Chemistry and Physics, vol. 98, no. 2-3, pp. 523-527, 2006.

[47] W.-W. Wang and Y.-J. Zhu, "Synthesis of needle-like and flowerlike zinc oxide by a simple surfactant-free solution method," Chemistry Letters, vol. 33, no. 8, pp. 988-989, 2004.

[48] A. Pan, R. Yu, S. Xie, Z. Zhang, C. Jin, and B. Zou, "ZnO flowers made up of thin nanosheets and their optical properties," Journal of Crystal Growth, vol. 282, no. 1-2, pp. 165-172, 2005.

[49] C. Lu, L. Qi, J. Yang, L. Tang, D. Zhang, and J. Ma, "Hydrothermal growth of large-scale micropatterned arrays of ultralong $\mathrm{ZnO}$ nanowires and nanobelts on zinc substrate," Chemical Communications, no. 33, pp. 3551-3553, 2006.

[50] W.-J. Li, E.-W. Shi, W.-Z. Zhong, and Z.-W. Yin, "Growth mechanism and growth habit of oxide crystals," Journal of Crystal Growth, vol. 203, no. 1, pp. 186-196, 1999. 
[51] S. W. Thomas III and T. M. Swager, "Trace hydrazine detection with fluorescent conjugated polymers: a turn-on sensory mechanism," Advanced Materials, vol. 18, no. 8, pp. 1047-1050, 2006.

[52] F. Xu, Z. Y. Yuan, G. H. Du, M. Halasa, and B. L. Su, "High-yield synthesis of single-crystalline $\mathrm{ZnO}$ hexagonal nanoplates and accounts of their optical and photocatalytic properties," Applied Physics A, vol. 86, no. 2, pp. 181-185, 2007.

[53] N. Wang, H. Lin, J. Li et al., "Strong orange luminescence from a novel hexagonal $\mathrm{ZnO}$ nanosheet film grown on aluminum substrate by a simple wet-chemical approach," Journal of the American Ceramic Society, vol. 90, no. 2, pp. 635-637, 2007.

[54] B. Cao, W. Cai, Y. Li, F. Sun, and L. Zhang, "Ultravioletlight-emitting $\mathrm{ZnO}$ nanosheets prepared by a chemical bath deposition method," Nanotechnology, vol. 16, no. 9, pp. 17341738, 2005.

[55] M. N. R. Ashfold, R. P. Doherty, N. G. Ndifor-Angwafor, D. J. Riley, and Y. Sun, "The kinetics of the hydrothermal growth of ZnO nanostructures," Thin Solid Films, vol. 515, no. 24, pp. 8679-8683, 2007.

[56] Y. Sun, D. J. Riley, and M. N. R. Ashfbld, "Mechanism of $\mathrm{ZnO}$ nanotube growth by hydrothermal methods on $\mathrm{ZnO}$ filmcoated Si substrates," The Journal of Physical Chemistry B, vol. 110, no. 31, pp. 15186-15192, 2006.

[57] K. Govender, D. S. Boyle, P. B. Kenway, and P. O'Brien, "Understanding the factors that govern the deposition and morphology of thin films of $\mathrm{ZnO}$ from aqueous solution?" Journal of Materials Chemistry, vol. 14, no. 16, pp. 2575-2591, 2004.

[58] L. Vayssieres, K. Keis, A. Hagfeldt, and S.-E. Lindquist, "Threedimensional array of highly oriented crystalline $\mathrm{ZnO}$ microtubes," Chemistry of Materials, vol. 13, no. 12, pp. 4395-4398, 2001.

[59] Q. Yu, W. Fu, C. Yu et al., "Fabrication and optical properties of large-scale $\mathrm{ZnO}$ nanotube bundles via a simple solution route," Journal of Physical Chemistry C, vol. 111, no. 47, pp. 17521-17526, 2007.

[60] A. Wei, X. W. Sun, C. X. Xu et al., "Growth mechanism of tubular $\mathrm{ZnO}$ formed in aqueous solution," Nanotechnology, vol. 17, pp. 1740-1744, 2006.

[61] A. Sugunan, H. C. Warad, M. Boman, and J. Dutta, "Zinc oxide nanowires in chemical bath on seeded substrates: role of hexamine," Journal of Sol-Gel Science and Technology, vol. 39, no. 1, pp. 49-56, 2006.

[62] H. Sun, M. Luo, W. Weng et al., "Room-temperature preparation of $\mathrm{ZnO}$ nanosheets grown on $\mathrm{Si}$ substrates by a seed-layer assisted solution route," Nanotechnology, vol. 19, no. 12, Article ID 125603, 2008.

[63] A. El Hichou, A. Kachouane, J. L. Bubendorff et al., "Effect of substrate temperature on electrical, structural, optical and cathodoluminescent properties of $\operatorname{In}_{2} \mathrm{O}_{3}$-Sn thin films prepared by spray pyrolysis," Thin Solid Films, vol. 458, no. 1-2, pp. 263268, 2004.

[64] X. M. Teng, H. T. Fan, S. S. Pan, C. Ye, and G. H. Li, "Photoluminescence of $\mathrm{ZnO}$ thin films on Si substrate with and without ITO buffer layer," Journal of Physics D: Applied Physics, vol. 39, no. 3, pp. 471-476, 2006.

[65] Y. Sakurai, "The $3.1 \mathrm{eV}$ photoluminescence band in oxygendeficient silica glass," Journal of Non-Crystalline Solids, vol. 271, no. 3, pp. 218-223, 2000.

[66] P. M. R. Kumar, K. P. Vijayakumar, and C. S. Kartha, "On the origin of blue-green luminescence in spray pyrolysed $\mathrm{ZnO}$ thin films," Journal of Materials Science, vol. 42, no. 8, pp. 2598-2602, 2007.

[67] A. Janotti and C. G. van de Walle, "New insights into the role of native point defects in ZnO," Journal of Crystal Growth, vol. 287, no. 1, pp. 58-65, 2006.

[68] T. Sekiguchi, K. Haga, and K. Inaba, " $\mathrm{ZnO}$ films grown under the oxygen-rich condition," Journal of Crystal Growth, vol. 214215, pp. 68-71, 2000.

[69] W. Cheng, P. Wu, X. Zou, and T. Xiao, "Study on synthesis and blue emission mechanism of $\mathrm{ZnO}$ tetrapodlike nanostructures," Journal of Applied Physics, vol. 100, no. 5, Article ID 054311, 2006.

[70] Z. Fang, Y. Wang, D. Xu, Y. Tan, and X. Liu, "Blue luminescent center in ZnO films deposited on silicon substrates," Optical Materials, vol. 26, no. 3, pp. 239-242, 2004.

[71] R. Wu, Y. Yang, S. Cong et al., "Fractal dimension and photoluminescence of $\mathrm{ZnO}$ tetrapod nanowhiskers," Chemical Physics Letters, vol. 406, no. 4-6, pp. 457-461, 2005.

[72] L. Wang, X. Zhang, S. Zhao, G. Zhou, Y. Zhou, and J. Qi, "Synthesis of well-aligned $\mathrm{ZnO}$ nanowires by simple physical vapor deposition on $c$-oriented $\mathrm{ZnO}$ thin films without catalysts or additives," Applied Physics Letters, vol. 86, no. 2, Article ID 024108, 2005.

[73] Z. Chen, N. Wu, Z. Shan et al., "Effect of N2 flow rate on morphology and structure of $\mathrm{ZnO}$ nanocrystals synthesized via vapor deposition," Scripta Materialia, vol. 52, no. 1, pp. 63-67, 2005.

[74] D. H. Zhang, Z. Y. Xue, and Q. P. Wang, "The mechanisms of blue emission from $\mathrm{ZnO}$ films deposited on glass substrate by r.f. magnetron sputtering," Journal of Physics D: Applied Physics, vol. 35, no. 21, pp. 2837-2840, 2002.

[75] X. Wei, B. Man, C. Xue, C. Chen, and M. Liu, "Blue luminescent center and ultraviolet-emission dependence of $\mathrm{ZnO}$ films prepared by pulsed laser deposition," Japanese Journal of Applied Physics, vol. 45, no. 11, pp. 8586-8591, 2006.

[76] Z.-X. Fu, C.-X. Guo, B.-X. Lin, and G.-H. Liao, "Cathodoluminescence of ZnO films," Chinese Physics Letters, vol. 15, no. 6, pp. 457-459, 1998.

[77] M. J. Zheng, L. D. Zhang, G. H. Li, and W. Z. Shen, "Fabrication and optical properties of large-scale uniform zinc oxide nanowire arrays by one-step electrochemical deposition technique," Chemical Physics Letters, vol. 363, no. 1-2, pp. 123$128,2002$.

[78] S. A. Studenikin, N. Golego, and M. Cocivera, "Fabrication of green and orange photoluminescent, undoped $\mathrm{ZnO}$ films using spray pyrolysis," Journal of Applied Physics, vol. 84, no. 4, pp. 2287-2289, 1998.

[79] R. B. M. Cross, M. M. de Souza, and E. M. S. Narayanan, "A low temperature combination method for the production of $\mathrm{ZnO}$ nanowires," Nanotechnology, vol. 16, no. 10, pp. 2188-2192, 2005.

[80] L. E. Greene, M. Law, J. Goldberger et al., "Low-temperature wafer-scale production of $\mathrm{ZnO}$ nanowire arrays," Angewandte Chemie International Edition, vol. 42, no. 26, pp. 3031-3034, 2003.

[81] H. Zhou, H. Alves, D. M. Hofmann et al., "Behind the weak excitonic emission of $\mathrm{ZnO}$ quantum dots: $\mathrm{ZnO} / \mathrm{Zn}(\mathrm{OH})_{2}$ coreshell structure," Applied Physics Letters, vol. 80, no. 2, pp. 210212, 2002.

[82] A. B. Djurisic, K. H. Tam, C. K. Cheung et al., "Defect in Zinc oxide nanostructures synthesized by a hydrothermal method," Nanoscale Phenomena, vol. 2, pp. 117-130, 2007. 
[83] A. B. Djurišić, Y. H. Leung, K. H. Tam et al., "Defect emissions in $\mathrm{ZnO}$ nanostructures," Nanotechnology, vol. 18, no. 9, Article ID 095702, 2007.

[84] R. B. Lauer, "The I.R. photoluminescence emission band in ZnO," Journal of Physics and Chemistry of Solids, vol. 34, no. 2, pp. 249-253, 1973.

[85] M. Koyano, P. Quocbao, L. T. Thanhbinh, L. Hongha, N. Ngoclong, and S. Katayama, "Photoluminescence and raman spectra of $\mathrm{ZnO}$ thin films by charged liquid cluster beam technique," Physica Status Solidi (A), vol. 193, pp. 125-131, 2002.

[86] M. Gomi, N. Oohira, K. Ozaki, and M. Koyano, "Photoluminescent and structural properties of precipitated $\mathrm{ZnO}$ fine particles," Japanese Journal of Applied Physics, vol. 42, no. 2 A, pp. 481-485, 2003.

[87] X. Q. Meng, D. Z. Shen, J. Y. Zhang et al., "The structural and optical properties of $\mathrm{ZnO}$ nanorod arrays," Solid State Communications, vol. 135, no. 3, pp. 179-182, 2005.

[88] Y. Q. Chen, J. Jiang, Z. Y. He, Y. Su, D. Cai, and L. Chen, “Growth mechanism and characterization of $\mathrm{ZnO}$ microbelts and selfassembled microcombs," Materials Letters, vol. 59, no. 26, pp. 3280-3283, 2005.

[89] R. C. Wang, C. P. Liu, J. L. Huang, and S.-J. Chen, "ZnO hexagonal arrays of nanowires grown on nanorods," Applied Physics Letters, vol. 86, no. 25, Article ID 251104, pp. 1-3, 2005.

[90] H. T. Ng, B. Chen, J. Li et al., "Optical properties of singlecrystalline $\mathrm{ZnO}$ nanowires on m-sapphire," Applied Physics Letters, vol. 82, no. 13, pp. 2023-2025, 2003.

[91] Z. Chen, N. Wu, Z. Shan et al., "Effect of $\mathrm{N}_{2}$ flow rate on morphology and structure of $\mathrm{ZnO}$ nanocrystals synthesized via vapor deposition," Scripta Materialia, vol. 52, no. 1, pp. 63-67, 2005.

[92] S. A. Studenikin, N. Golego, and M. Cocivera, "Fabrication of green and orange photoluminescent, undoped $\mathrm{ZnO}$ films using spray pyrolysis," Journal of Applied Physics, vol. 84, no. 4, pp. 2287-2294, 1998.

[93] Y. M. Sun, FP-LMTO study on the electronic structure of $\mathrm{ZnO}$ and its defects [Ph.D. thesis], University of Science and Technology of China, 2000.

[94] B. Lin, Z. Fu, and Y. Jia, "Green luminescent center in undoped zinc oxide films deposited on silicon substrates," Applied Physics Letters, vol. 79, no. 7, pp. 943-945, 2001.

[95] K. Vanheusden, C. H. Seager, W. L. Warren, D. R. Tallant, and J. A. Voigt, "Correlation between photoluminescence and oxygen vacancies in ZnO phosphors," Applied Physics Letters, vol. 68, no. 3, pp. 403-405, 1996.

[96] F. Tuomisto, K. Saarinen, D. C. Look, and G. C. Farlow, "Introduction and recovery of point defects in electron-irradiated ZnO," Physical Review B: Condensed Matter and Materials Physics, vol. 72, no. 8, Article ID 085206, 2005. 

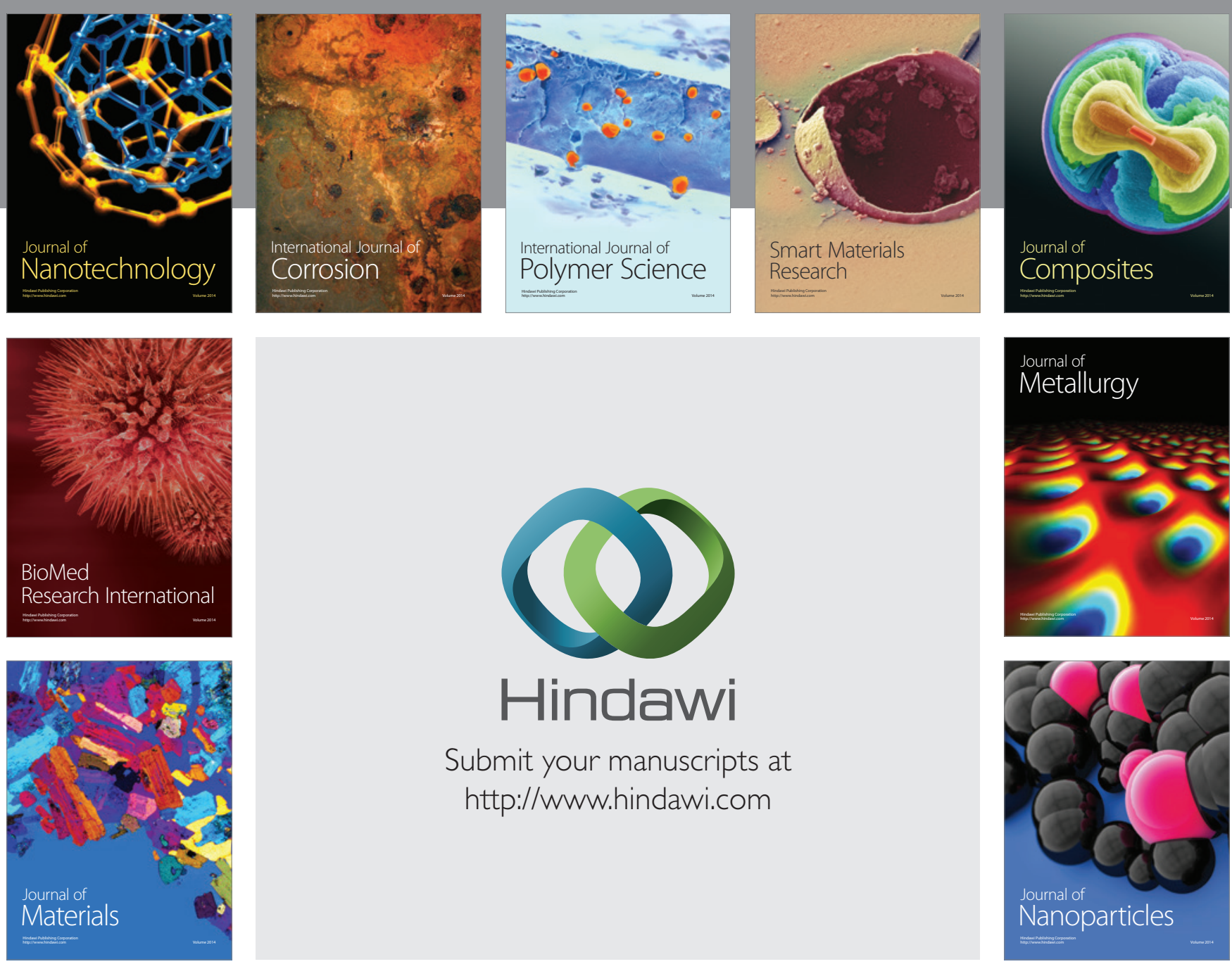

Submit your manuscripts at http://www.hindawi.com
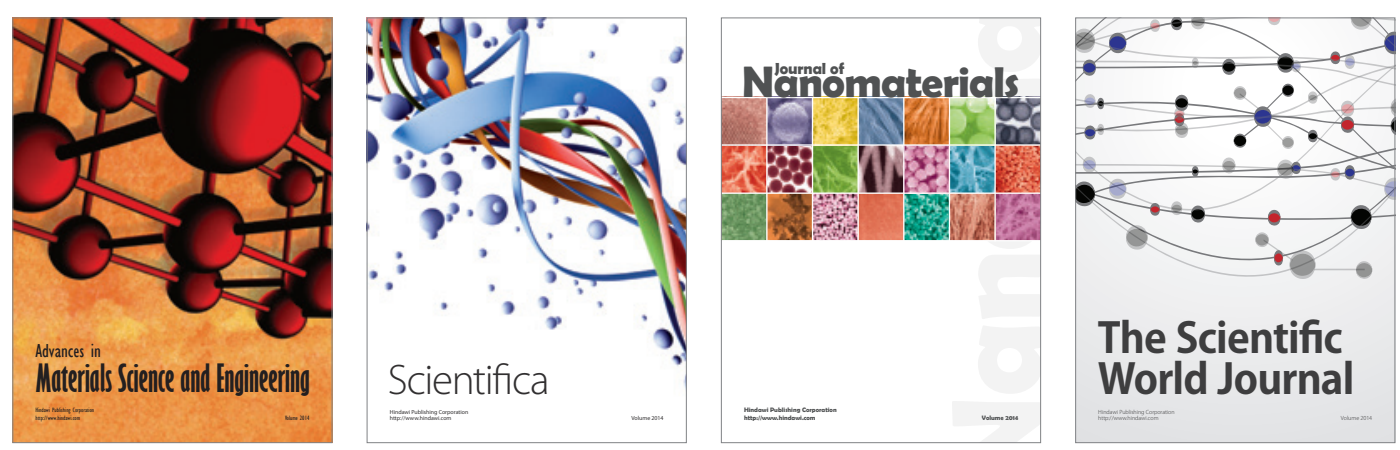

\section{The Scientific World Journal}
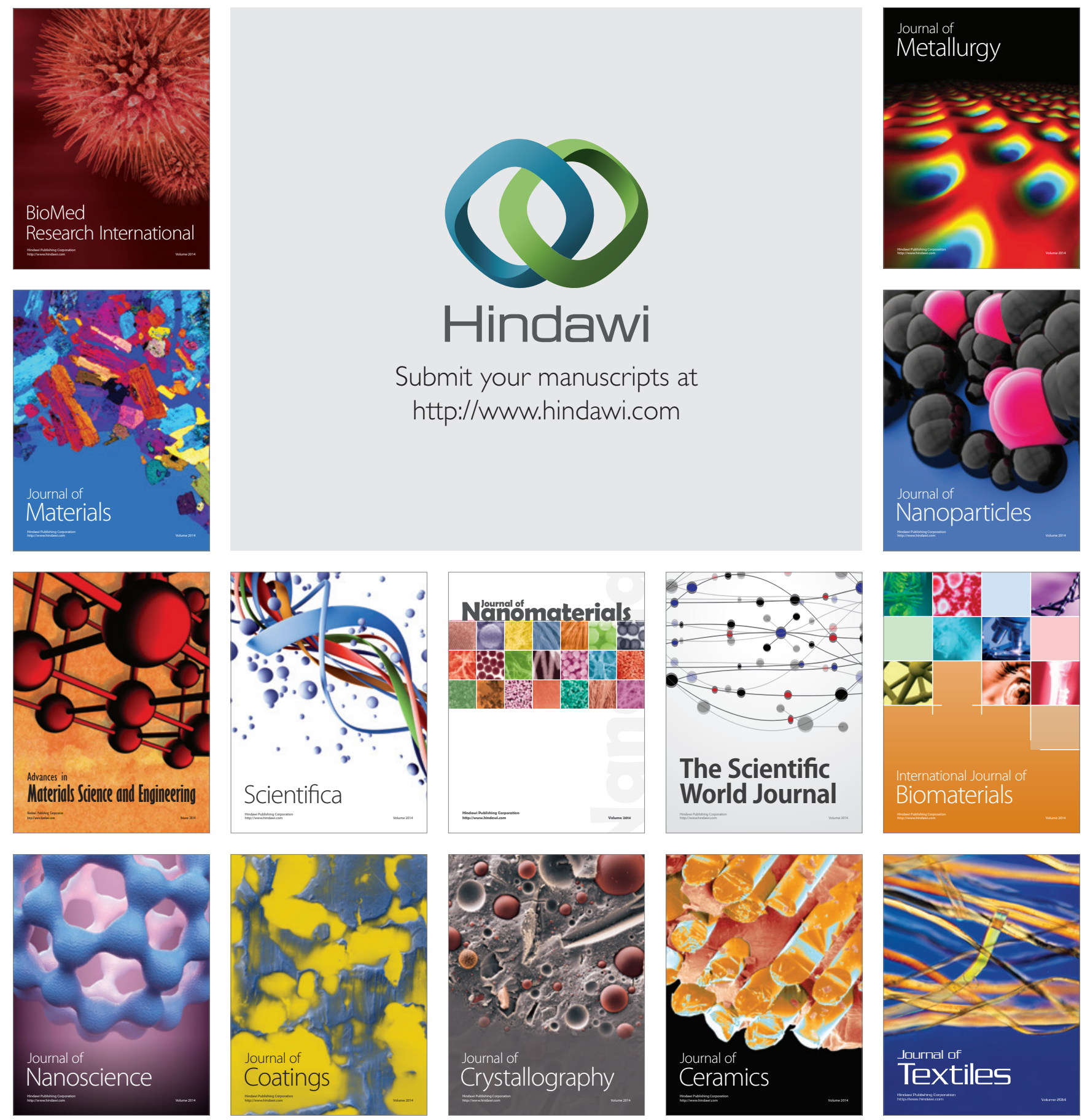